\title{
Theoretical Aspects, Modern Treatment Options and Practical Case Presentations in Hip and Knee Tumoral and Revision Bone Defect Reconstruction Surgery
}

\author{
GEORGE DINACHE ${ }^{1,2 *}$, MARINEL DRIGNEI ${ }^{3}$, STERGIOS GANATSIOS ${ }^{4}$, ERIC J OVENET ${ }^{5}$, RADU COSTEA2, \\ FLORIN SAVULESCU ${ }^{1}$, STELIAN LUPASCU ${ }^{1}$ \\ ${ }^{1}$ Dr. Carol Davila Central Universitary Emergency Military Hospital , 134 Calea Plevnei , 010825, Bucharest, Romania) \\ ${ }^{2}$ Carol Davila University of Medicine and Pharmacy Bucharest, 37 Dionisie Lupu Str., 020021, Bucharest, Romania \\ ${ }^{3}$ Abbeville Hospital Center, Abbeville, France \\ ${ }^{4}$ T.E.I.W.M., Kila Kozani 50100, Kila, Grece \\ ${ }^{5}$ JMS, 1929 Seche Rue, 62149, Festubert
}

\begin{abstract}
Bone defects are a challenge to any and in fact every orthopedic surgeon, be they as a consequence of trauma, peri-implant bone loss as is the case in revision surgery or, more often than not, in tumors of the bone. These defects are in most cases difficult to reconstruct, but even more so in the case when they are located around the major joints of the lower limb, i.e. the hip and the knee. We focus in this article on acetabular bone defects as well as on defects around the knee (distal femur and proximal tibia). We present implant possibilities and modern means of reconstructing the bone defect using augments. We also present three representative cases from our Clinic, to further exemplify the discussed concepts. We present our opinions on reconstructing bone defects after tumor and revision surgery in the hip and knee and we draw conclusions.
\end{abstract}

Keywords: bone defects, acetabulum, knee, tumor, 3D printing, reconstruction

\section{Revision hip surgery}

The difficulties that the surgical team faces when dealing with an acetabular bone defect are among the greatest challenges in hip surgery [1-4].The acetabular reconstruction in total hip revision surgery may be met with success by using biomaterial components with a porous surface, and multiple screws in the case of minor acetabular defects $[5,6]$.

The choice of acetabular components is mostly based on the size of the existing bone defect $[7,8]$ In the presence of combined cavitary and segmentary defects, reconstruction using an acetabular allograft protected with a cage is the preferred variant of the surgical options [9], but numerous complications of this procedure are described, among which: loosening of the acetabular component, infection, dislocation and montage degradation [10-14]. Modification of the axis of the limb is possible, with long-term effects including osteoarthritis in the knee, sometimes dealt with arthroscopically [15], other times requiring an arthroplasty [16].

A modern alternative is the TMARS [17] - the trabecular metallic acetabular revision system that has the following models of acetabular and auxiliary implants:

-the metallic trabecular shell is designed to be used in revision cases, placed so that there is a maximum of bone contact. The reduced elasticity module of the trabecular metallic material produces a normal physiologic force transmission and may reduce the level of stress shielding. The shell's characteristics include an elliptic geometry for maximizing bone contact, thus improving initial stability, and also holes for screws that allow for a long-lasting supplementary fixation.

-the metallic trabecular cup is used in combination with the metallic trabecular revision shell in order to ensure an adequate stability by eliminating acetabular defects and pelvic discontinuities. This component is fabricated of pure titanium for an optimized mechanical resistance, is available in left and right configurations and is constructed to match the individual anatomy of the patient.

-the metallic trabecular screws that work together with the revision shell in order to deal with superior segmentary defects are used as an alternative to an allograft, with zero potential of resorbtion, and preserving the patient's bone stock while the dimension, position and orientation of the implant are determined by the defect, which allows for the center of the femoral head to be restored, optimizing the patient's kinetics.

-the metallic trabecular augmentation and restriction components have the purpose of filling bone defects as an alternative to preparing and using structural grafts. The interfaces are cemented creating a monolithic construct, the restrictor is concave and available in three diameters in order to fill a bone defect.

Salvage surgery of the lower limb remains a challenge of oncologic orthopedic surgery. The distal femur and the proximal tibia are the main localizations of primary bone tumors, the osteosarcoma and the Ewing sarcoma being among the most frequent. The new imaging techniques and the recent development of chemotherapy and surgical protocols have lead to an improvement in the management of these tumors, allowing for a decrease in the number of radical procedures - amputations. Resection and total knee arthroplasty have become the gold standard for these tumors when located around the knee [18]. When the tumor is extended beyond surgical resection limits, an amputation is the only viable option, followed by the use of an external prosthesis, often times with a modern myoelectric command system [19, 20].

Modular prosthesis are widely used to treat defects of various sizes and their introduction has represented a new 
era in oncologic orthopedics. They use a press fit fixation within healthy bone tissue, thanks to the long centromedullary stems, butalso a cemented fixation, while respecting strict oncologic resection limits. All these systems of prosthetics have unsatisfactory results in the long term, when compared to the primary knee prosthesis, because of the large defects that need to be replaced, with a much more difficult fixation in the femoral and the tibial diaphysis and a much more difficult recovery due to the knee's biomechanics. Frequent complications include infection and loosening. Despite all this, such an endoprosthesis represents a valuable line of treatment, despite the existing problems in bone fixation, which imposes that the procedure is done in a specialized center. Among the advantages of this prosthesis one would count an early loading of the affected lower limb, a relatively good knee function and an early social and professional reintegration [21].

The high modularity of the Link Megasystem-C [22] allows for intraoperative flexibility, in-surgery adjustment of leg length and a wide range of indications: a tumor in the distal femur and / or the proximal tibia as well as a revision arthroplasty due to post-traumatic juxtaarticular segmentary bone defects.

The preoperative planning is crucial and much attention is given to the evaluation of the extensor mechanism, its preservation and when necessary, its consolidation. A careful planning before implanting the endoprosthesis: choice of surgical procedure, resection limits, implant selection and its alignment leads to a minimisation of the risk of complications. Planning may be done in a traditional manner, by superimposing sketches of the prosthesis on top of the x-rays of the patient, a method that is subject to error, or by using a more modern automated method that uses reconstruction and $3 \mathrm{D}$ printing of the bone tissue that is affected by the tumour, allowing for a more accurate estimate of the surgical difficulties and also allowing for a shortening of the operative time [23-27]. Also a part of planning is the evaluation of the vascular and nervous axis of the knee, even including an angiographic evaluation, as well as of the soft tissues that envelope the joint, a biopsy, an anatomopathological examination and a staging of the tumoral lesion. Pre-existing conditions, such as cardiac pathology, are to be evaluated and an efficient treatment is to be started in order to allow for surgery, with a carefull evaluation of the efficacy of the treatment $[28,29]$. A carefull planning minimises the risk of malpositioning the prosthesis, with a modification in the axis of transmission of the forces in the lower limb, with various consequences such as plantar arch collapse and subsequent plantar fasciitis, which may hinder recovery and may be dealt in various manners [30].

The purpose of using a megaprosthesis is to obtain a control of the evolution of the disease that is as efficient as an amputation, while preserving the limb in a functional, long-lasting manner.

In the literature the attention is focused more on the survival of the limb (there is a high risk of tumoral recurrence) and on the complications that affect the implant in itself, rather than on the postoperative function of the limb [31]. The MSTS score (Musculoskeletal Tumor Society) is a widely used and accepted tool for measuring the functional response. This score has six sections, gradually describing pain from 1 to 5 , general function, emotional acceptance and specific function of the inferior limb (the ability to walk, the characteristics of walking, and the need for support during walking) [32].

In all, tumoral megaprosthesis offer a functional limb in a satisfactory number of patients over a satisfactory period of time. The great survival rate in time of upper limb implants when compared to lower limb implants is noted, especially in the knee area, and a challenge remains in identifying with precision the factors that allow endoprosthesis to bear the mechanical and biologic stress in patients with an increased life expectancy.

\section{Experimental part}

\section{Materials and methods}

Bone defects, whether in the hip or the knee areas, should be thoroughly investigated visually, as is the case with this 65 year old female patient preparing for an atypical total knee arthroplasty that may require an augment (figs. 1-3).

Case 1

We present the case of C.M., a 81 year old female patient, which presented in may 2018 to our clinic with pain and functional impairment of her left hip. The patient was known to have a cemented total hip endoprosthesis implanted in 2000 , without incidents, and had no notable problems with her prosthesis until the last 6 months. The patient is also known to have a grade III obesity and hepatitis $C$.

A native pelvis CT was performed and it revealed a Paprosky IIA acetabular loosening (figs. 4-6).

\section{Case 2}

We present the case of B.A., a 66 year old male patient who presented with pain and functional impairment in his left hip in march 2018. Initially the patient had a total uncemented hip arthroplasty performed in 2012, for
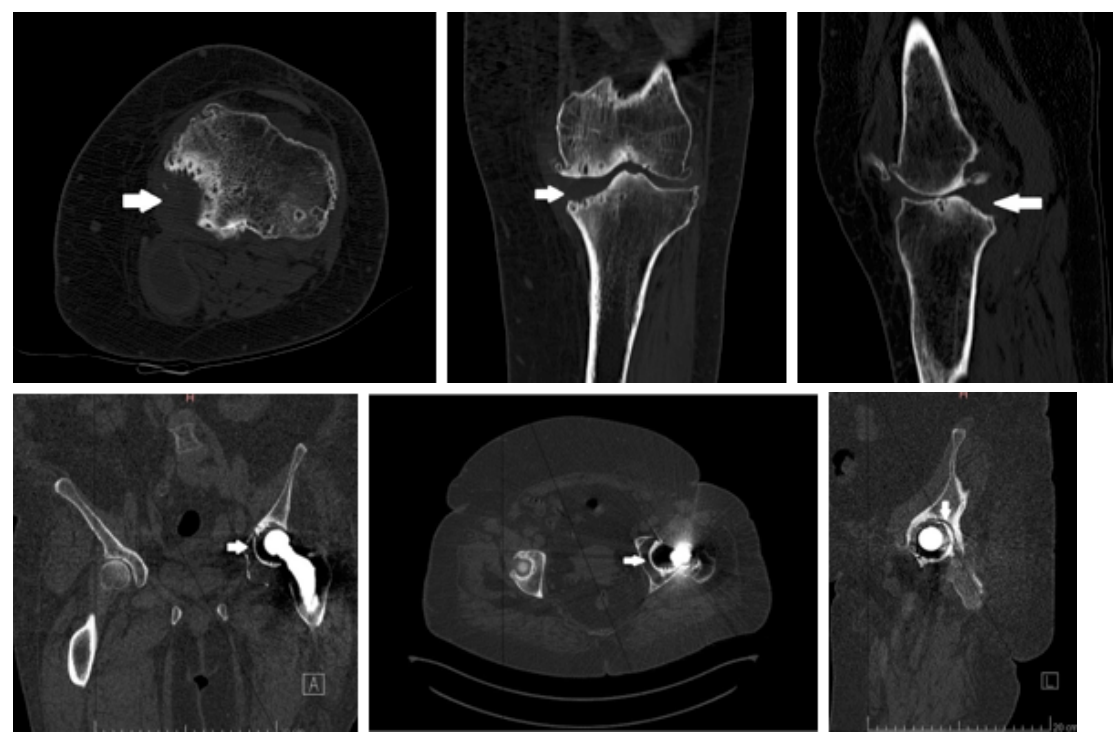

Figs. 1-3. Preoperative CT captures of a lateral tibial plateau defect, as seen in the axial (1), coronal (2) and sagittal (3) planes 
osteoarthrosis of the hip. In 2016 the patient presented with significant pain and functional impairment in the left hip and, after radiologic investigations, was diagnosed with loosening of the acetabular component. A revision was performed with a cemented cup, with a significant superior acetabular defect being filled with PMMA ortopedic cement(fig. 7); in 2017 he was diagnosed with loosening of both acetabular and femoral components of the prosthesis, with an associated inflammatory syndrome, but without an identified pathogen. In 2017 the prosthesis was extracted and replaced with a cement spacer. In 2018 the patient reported to our clinic for total hip revision

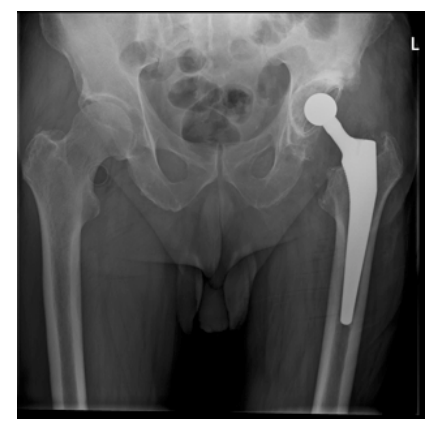

Fig. 7. A hybrid hip prosthesis (cemented cup, uncemented stem) as a result of revision

surgery of a loosened uncemented acetabular cup, resulting in a large defect that was filled with cement.

arthroplasty, after a year with the spacer, and with a remissed inflammatory syndrome.

Case 3

We present the case of G.N., a 44 year old male patient, who presented in 2016 to our clinic with a small osteolitic
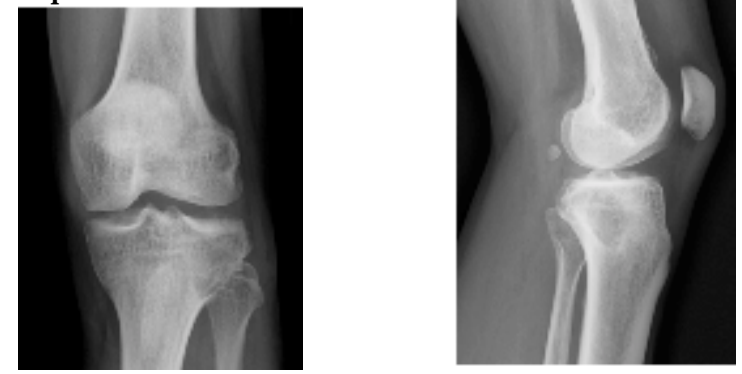

Figs. 8, 9. Lateral tibial plateau showing an osteolytic tumor, as seen in AP (8) and LL (9) x-rays of the patients knee

mass in the proximal tibial metaphysis, with no other known commorbidities (figs. 8 and 9).

An excisional biopsy was perfomed and the anatomopathological result was chondrosarcoma of the

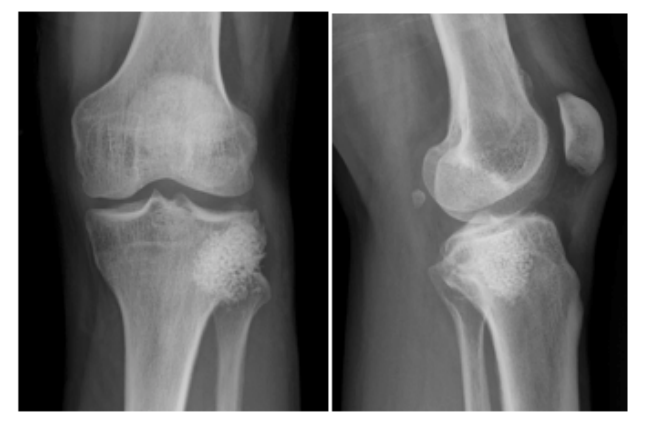

Figs. 10, 11. An chondrosarcoma of the lateral tibial plateau has been excised and the defect has been filled with bone substitute, as seen in AP (10) and LL (11) x-rays of the patients knee

tibial plateau; the defect was filled with a bone substitute (figs. 10 and 11).
In 2018 the tumoral osteolytic lesion had reappeared and progressed and the decision was made to perform a resection and a reconstruction with a tumoral prosthesis.

\section{Results and discussions}

\section{Case 1}

In the case of 81 year old C.M. a hip prosthesis revision surgery was performed through a posterolateral approach, extracting the loosened acetabular component and finding an approximately $2 \times 3 \times 2 \mathrm{~cm}$ bone defect. The acetabulum was prepared with the Trabecular Metal Acetabular Revision System (TMARS) from Zimmer (17), which include a revision shell (Acetabular Revision Shell Tantalum/Titanium Alloy) with a polyethylene insert

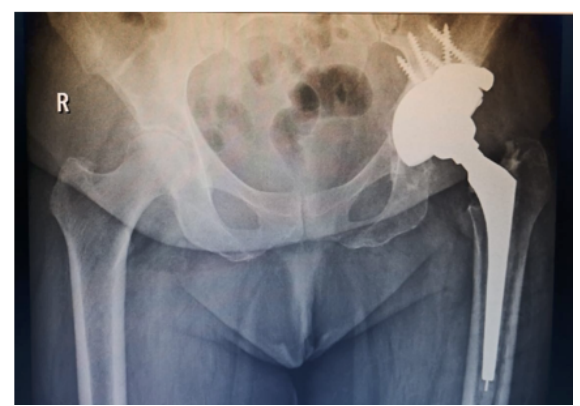

Fig. 12. The Trabecular Metal Acetabular Revision System (TMARS) from Zimmer used to revise a loosened hip prosthesis with a particlarly large acetabular defect

(Longevity Highly Crosslinked Polyethylene Revision Shell Liner Cemented) and a tantalum augment (Acetabular Augment Tantalum) (fig. 12).

Postoperative, the patient was given standard antibiotics therapy, antiinflammatory drugs and anticoagulant treatment (Nadroparin calcium f $0.6 \mathrm{~mL}$ fo 30 days). She was instructed to walk non-weight-bearing and to use a walker for 45 days, followed by partial weight bearing for 3-4 weeks then using a cane as needed while the pain subsides. Physical therapy was prescribed.

The evolution was favorable, with the patient returning to a pain-free normal active lifestyle within three months of the operation.

\section{Case 2}

In the case of 66 year old B.A., a total left hip revision procedure was performed in march 2018, with a the Trabecular Metal Acetabular Revision System (TMARS) from Zimmer [17], vis a posterolateral approach (figs. 13 and 14). The acetabular defect was reamed and a revision shell (Acetabular Revision Shell - Tantalum/Titanium Alloy) was impacted, secured with screws, onto which a polyethylene insert (Longevity Highly Crosslinked Polyethylene Revision Shell Liner Cemented) was cemented. Postoperative, non weight bearing on the left leg was advised for 45 days, and, as per protocol, a 14 day antibiotics treatment and a 30 days oral anticoagulant treatment was prescribed. The patient resumed partial weight bearing after 45 days and total weight bearing after another 14 days, reporting excellent function of the left hip

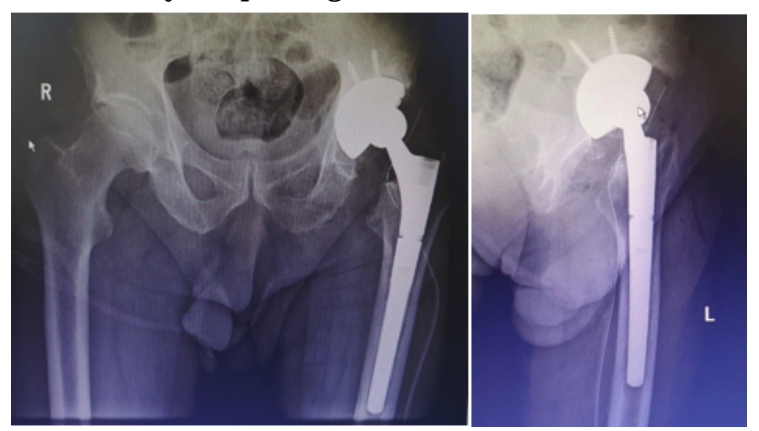

Figs. 13, 14. The Trabecular Metal Acetabular Revision System (TMARS) from Zimmer used to revise a loosened hip prosthesis with an acetabular defect, AP (13) and LL (14) xrays of the hip 
The suspected pathogen was not identified, nor did the inflammatory syndrome reappear.

\section{Case 3}

In the case of 44 year old G.N., we performed a resection of the proximal tibial metaphysis with the tumoral mass being removed en-bloc, and a reconstruction using the MEGASYSTEM-C from Link [22], a tumoral and reconstruction prosthesis using Cobalt-Chrome-Molibden Alloy, Tilastan, Ti-6Al-4V and UHMWPE components, cemented using the gentamicin PMMA acrylic cement Gentafix 1 fromTeknimed [33] (figs. 15-20).

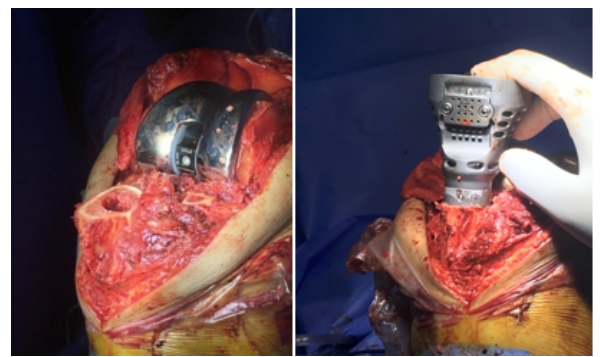

FIgs. 15, 16. Removal of a proximal tibial tumor and reconstruction using the MEGASYSTEM-C from Link; implantation of the femoral

(15) and tibial (16) components.

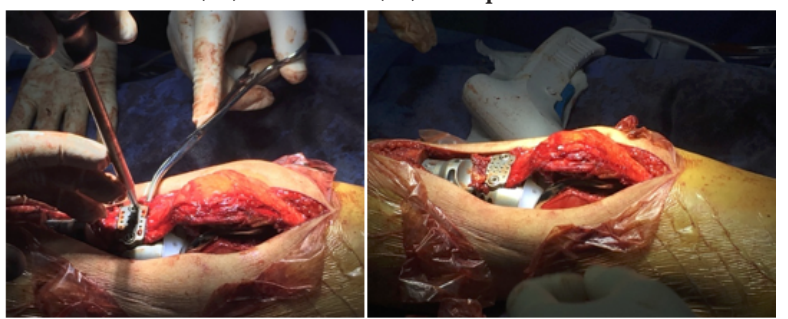

Figs. 17, 18. Reattachment of the extensor mechanism of the knee to the tibial component of the MEGASYSTEM-C: fixation of the plate (17) and final aspect (18).

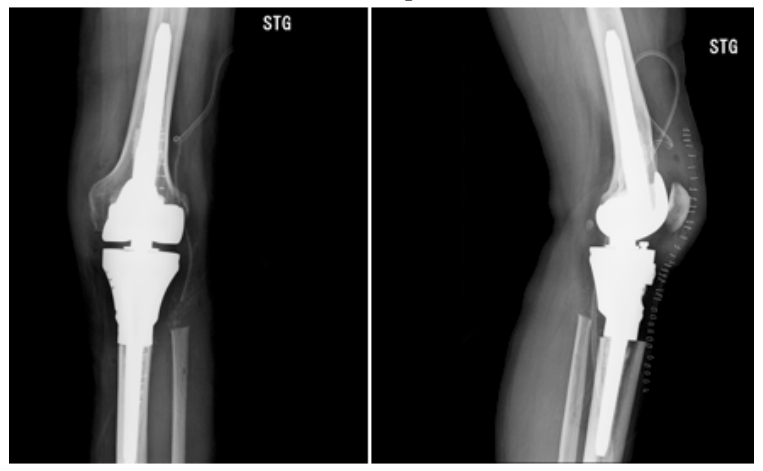

Figs. 19, 20. The MEGASYSTEM-C tumoral revision knee prostesis, as seen in AP (19) and LL (20) postoperative x-rays of the patients knee

As per protocol, 7 days of prophyllactic antibiotic was prescribed -Ciprofloxacin $500 \mathrm{mg}$ every $12 \mathrm{~h}$, as well as antithrombotic prophillactic Nadroparin calcium f $0.4 \mathrm{~mL}$ once daily for 30 days was prescribed. The patient resumed full weight bearing immediatly postoperative, and used a walker for 30 days, then a cane until pain subsided. At three months the clinical result is good, and xrays show no osteolytic lesions. The patient is under oncologic treatment and monitorisation.

Bone defects around the major joints of the lower limb, whether tumoral (primitive or metastasis) or as a consequence of aseptic or septic loosening of an implant, remain a serious problem of histopathological diagnosis and of treatment.

The histopathological and immunohistochemical diagnosis remain the standard in establishing the type of bone tumor, and the multidisciplinary treatment (orthopedic surgery, general surgery, plastic surgery, neurosurgery, oncology, clinical immunology, radiotherapy) should include establishing at hospital level (usually an university hospital) of an oncologic case comity and establishing each specialty's therapeutic times.

The ideal goal of surgical treatment is to remove the tumor in oncologic limits by sacrificing bone and soft tissue capital that generally make bone reconstruction and joint function impossible. It is because of this broad resection, often times impossible without amputating the respective segment, that an urgent precise histopathological diagnosis is required, usually done by incisional biopsy.

The main challenge facing the orthopedic surgeon is making a decision in accordance with the technical possibilities of the clinic where his or her activity is done, with the resources of the intensive care unit and the disponibility of an internal bone reconstruction medical device.

If for segmentary resections of the diaphysis various reconstruction techniques exist (resection, reconstruction using a static contromedullary nail, orthopedic cement filling, the lifting technique with ulterior reconstruction, vascularised peroneus graftetc), for epiphysis tumors and for epiphysis revision defects the only solution, except for amputating the segment, remain the tumor reconstruction prosthesis, with a high financial cost, but also with many advantages:

-the psychological comfort of the patient, retaining the respective limb segment;

-a total or partial reclaim of function for the segment;

- a rapid socio-professional reintegration of the patient.

The obtained results recommend further research in some interdisciplinary areas where robotic systems or virtual simulation environments are used [34 -41].

\section{Conclusions}

Although numerous revision and tumor reconstruction prosthesis exist, it is our belief that that main issue remains the interface (permanent throughout the time of survival of the patient) between the implant and the bone and we believe that this may be improved with clinical trials and research regarding the possibility of three-dimensional reconstruction of the bone defect through $3 \mathrm{D}$ printing, starting with a CT scan of the contra lateral healthy segment and ending with a personalized augment that exactly fills the existing defect, restoring the joint after fitting the prosthesis to a function as close to its natural one.

\section{References}

1. ISSACK P.S., NOUSIAINEN M., BEKSAC B., HELFET D.L., SCULCO T.P., BULY R.L. Acetabular component revision in total hip of major bone loss and pelvic discontinuity, Am J Orthop (Belle Mead NJ), 38, 2009, p. 550-6.

2. VAN HAAREN E.H., HEYLIGERS I.C., ALEXANDER F.G., WUISMAN P.I., High rate of failure of impaction grafting in large acetabular defects, J Bone Joint Surg Br., 89, 2007, p. 296-300.

3. BOSTROM M.P., LEHMAN A.P., BULY R.L., LYMAN S., NESTOR B.J ., Acetabular revision with the Contour antiprotrusio cage: 2- to 5-year followup, Clin Orthop Relat Res., 453, 2006, p. 188-94.

4. VAN EGMOND N., DE KAM D.C., GARDENIERS J.W., SCHREURS B.W., Revisions of extensive acetabular defects with impaction grafting and a cement cup, Clin Orthop Relat Res, 469, 2011, p. 562-573.

5. SPORER S.M., How to do a revision total hip arthroplasty: revision of the acetabulum, J Bone J oint Surg Am, 93, 2011, p. 1359-66.

6. BORLAND W.S., BHATTACHARYA R., HOLLAND J.P., BREWSTER N.T., Use of porous trabecular metal augments with impaction bone grafting in management of acetabular bone loss, Acta Orthop, 8, 2012, p. 347-52. 
7. YUN H.H., SHON W.Y., HONG S.J ., YOON J.R., YANG J.H., Relationship between the pelvic osteolytic volume on computed tomography and clinical outcome in patients with cementless acetabular components, Int Orthop, 35, 2011, p. 1453-9.

8. SUH D.H., HAN S.B., YUN H.H., CHUN S.K., SHON W.Y., Characterization of progression of pelvic osteolysis after cementless total hip arthroplasty: computed tomographic study, J Arthroplasty, 28, 2013, p. 1851-5.

9. GROSS A.E., GOODMAN S., The current role of structural grafts and cages in revision arthroplasty of the hip, Clin Orthop Relat Res, 429, 2004, p. 193-200.

10. ABOLGHASEMIAN M., TANGSATAPORN S., STERNHEIM A., BACKSTEIN D., SAFIR O., GROSS A.E., Combined trabecular metal acetabular shell and augment for acetabular revision with substantial bone loss: a mid-term review, Bone J oint J, 95, 2013, p. 166-72.

11. REILEY M.A., BOND D., BRANICK R.I., WILSON E.H., Vascular complications following total hip arthroplasty. A review of the literature and a report of two cases, Clin Orthop Relat Res, 186, 1984, p. 23-8.

12. BUTTARO M.A., COMBA F., PUSSO R., PICCALUGA F., Acetabular revision with metal mesh, impaction bone grafting, and a cemented cup, Clin Orthop Relat Res, 466, 2008, p. 2482-90.

13. PATEL S., SUKEIK M., HADDAD F.S., Initial implant stability predicts migration but not failure in cementless acetabular revision with bone grafting, J Arthroplasty, 28, 2013, 832-7.

14. AVCI S., CONNORS N., PETTY W., 2- to 10-year follow-up study of acetabular revisions using allograft bone to repair bone defects, J Arthroplasty, 13, 1998, p. 61-9.

15. MOGA, M., POGARASTEANU, M. E., EDU A., Arthroscopy in Arthrosis: Is It Worth it? - A case Presentation, Rev. Chim. (Bucharest), 69, no. 8, 2018, p. 2232-5.

16. ADAM R., ORBAN C., ORBAN H., Comparative Study of Design and PCL-Substituting Systems of Total Knee Prosthesis, Chirurgia, 109(1), 2014, P. 99-103.

17.***https://www.zimmerbiomet.com/content/dam/zimmer-biomet/ medical-professionals/hip/trabecular-metal-acetabular-revisionsystem/zimmer-trabecular-metal-acetabular-revision-system-tmarsbrochure.pdf. [Online] [Cited: Nov 12, 2018.]

18. MATTEI J.C., CURVALE G., ROCHWERGER A., Surgery in «around the knee» bone tumors, Bull Cancer, 101(6), 2014, p. 571-9.

19.S. OSICEANU, M. DASCALU, E. FRANTI, A. BARBILIAN, Intelligent Interfaces for Locomotory Prosthesis; IJ CNN: 2009 International J oint Conference on Neural Networks, Vol1-6; IEEE; IEEE International Conferences on Neural Networks (IJ CNN); Pages: 1933-1938; 2009; WOS: 000280591601024. Atlanta, J une 14-J une 19, 2009, USA

20. MOLDOVAN ,C., DOBRESCU, L., RISTOIU, V., FIRTAT, B., DINULESCU, S., BRASOVEANU, C., ION, M., DOBRESCU, D., GHEORGHE, R., PASCALAU, A.M., POGARASTEANU, M., COCULESCU, B.I., OPROIU, A.M, Experimental measurements in the acquisition of biosignals from a neuronal cell culture for an exoprosthesis command, Rev. Chim. (Bucharest), 69, no. 11, 2018, pg. 2948- 2952

21. GKAVARDINA A., TSAGOZIS P., The Use of Megaprostheses for Reconstruction of Large Skeletal Defects in the Extremities: A Critical Review, Open Orthop J, 8, 2014, p. 384-9.

22. *** http://www.linknederland.nl/_cache/link/media/ebosjc5796/ Link_Nederland_Mega_C_OK_techniek__01_2015.pdf. [Online] [Cited: Nov 28,2018 .]

23. PLAVITU, A., POGARASTEANU, M. E., MOGA, M., LUPUSORU, M., IONITA RADU, F., EDU, A., 3D Printing as a Way of Integrating Mathematical Models in Arthroscopic Knee Surgery, Rev. Chim. (Bucharest), 69, no. 9, 2018, p. 2501-7.

24. WANG F., ZHU J., PENG X., SU J.,The application of 3D printed surgical guides in resection and reconstruction of malignant bone tumor,Oncol Lett., 14(4), 2017, p. 4581-4584.

25. KRCAH M., SZEKELY G., BLANC R., Fully automatic and fast segmentation of the femur bone from 3D-CT images with no shape prior, Proceedings of the 8th IEEE International Symposium on Biomedical Imaging: From Nano to Macro, ISBI 2011, 2011.
26. KIM G., JUNG H.J ., LEE H.J ., LEE J .S., KOO S., CHANG S.H.,Accuracy and Reliability of Length Measurements on Three-Dimensional Computed Tomography Using Open-Source OsiriX Software,J Digit Imaging, 25(4), 2012,p. 486-491.

27. PLAVITU, A., POGARASTEANU, M.E., MOGA, M., BARBILIAN, C.R., STOICA, I.C., ROBU, G.C., OPROIU, A.M., JINGA, M., IFRIM, C.F., MRI versus $C T$ as image data source for $3 D$ printing bone, Rev. Chim. (Bucharest), 69, no. 10, 2018, p. 2881-4.

28. COCULESCU, B.I., DINCÃ, G.V., MANOLE, G., PURCAREA, V.L., OPROIU, A.M., STOCHECI, C.M., Serum Concentration of hSCRP Possible Marker for Therapy Evaluation in Left Ventricular Dysfunction with Preserved Ejection Fraction, Rev. Chim. (Bucharest), 69, no. 10, 2018, p. 2885-990.

29. NITA, D., GURZUN, M., CHIRIAC, L., CIRSTEA, A.I., PAREPA, R.I., BARBILIAN, A.G., Impact of stent diameter and length on in-stent restenosis after bare metal stent implantation, Romanian Biotechnological Letters, 22, no. 2, 2017, p. 1234-12351

30. MOGA, M., POGARASTEANU, M. E., EDU, A., Arthroscopic Equipment Used in the Treatment of Calcaneal Spurs - A case presentation, Rev. Chim. (Bucharest), 69, no. 8, 2018, p. 2228-31.

31. HEISEL C., KINKEL S., BERND L., EWERBECK V., Megaprostheses for the treatment of malignant bone tumours of the lower limbs, Int Orthop, 30(6), 2006, p. 452-7.

32. UEHARA K., OGURA K., AKIYAMA T., SHINODA Y., IWATA S., KOBAYASHI E., TANZAWA Y., YONEMOTO T., KAWANO H., KAWAI A., Reliability and Validity of the Musculoskeletal Tumor Society Scoring System for the Upper Extremity in Japanese Patients, Clin Orthop Relat Res, 475(9), 2017, p. 2253-9.

33.*** https://www.teknimed.com/portfolio-items/gentafix1/. [Online] [Cited: Nov 21, 2018.]

34. FRANTI, D. TUFIS, S. GOSCHIN, M. DASCALU, P. L. MILEA, G. STEFAN, T. BALAN, C. SLAV, R. DEMCO, Virtual environment for robots interfaces design and testing, CAS 2005,International Semiconductor Conference; IEEE; volume 1-2, pp. 463-466; 2005; WOS: 000237180300103

35.VEE SAN CHEONG, PAUL FROMME, AADIL MUMITH, MELANIE J.COATHUP, GORDON W.BLUNN, Novel adaptive finite element algorithms to predict bone ingrowth in additive manufactured porous implants, J ournal of the Mechanical Behavior of Biomedical Materials, Volume 87, November 2018, Pages 230-239

36. MOGA, M., SEMENESCU, A., CHIVU, R.D., COSTOIU, M.C.,MATES, I.M.,CALIN, C.I., AMZA, C. Gh.,POGARASTEANU, M.E., OPROIU, A.M., IONITA RADU,F., An Alternative Femoral Stem-Bone Implantation Technique Using an Innovative Short Femoral Stem Endoprosthesis, Rev. Chim. (Bucharest), 69, no. 11, 2018, p. 3299-3303.

37. SEKOU SINGARE, QIN LIAN, WEI PING WANG, JUE WANG, YAXIONG LIU, DICHEN LI, BINGHENG LU, Rapid prototyping assisted surgery planning and custom implant design, Rapid Prototyping J ournal, Vol. 15 Issue: 1, pp.19-23, 2009, https://doi.org/10.1108/13552540910925027, 38. OPROIU, A.M., LASCAR, I., DONTU, O., FLOREA, C., SCARLET, R., SEBE, I., DOBRESCU, L., MOLDOVAN, C., NICULAE, C., CERGAN, R., BESNEA, D., CISMAS, S., DAVID, D., MURARU, D., NEAGU, T., POGARASTEANU, M.E., STOICA, C., EDU, A., IFRIM, C.F., Topography of the Human Ulnar Nerve for Mounting a Neuro-Prosthesis with Sensory Feedback, Rev. Chim. (Bucharest), 69, no. 9, 2018, p. 24942497

39. JIHUI LI, FELASFA WODAJ O, MARK THEISS, MICHELLE KEW, ALISON J ARMAS, Computer Simulation Techniques in Giant Cell Tumor Curettage and Defect Reconstruction, Computing in Science \& Engineering 15, 21 (2013); https://doi.org/10.1109/MCSE.2012.130 40. TAN PK, TAN MH. Functional outcome study of mega-endoprosthetic reconstruction in limbs with bone tumour surgery. Ann Acad Med Singapore. 2009;38(3): 192-6.

41. A. M. OPROIU, I. LASCAR, C. MOLDOVAN, O. DONTU, M. PANTAZICA, C. MIHAILA, C. FLOREA, L. DOBRESCU, I. SEBE, R. SCARLET, D. DOBRESCU, T.NEAGU, O. IONESCU, I. C. STOICA and A. EDU, Peripheral Nerve WIFI Interfaces and Electrodes for Mechatronic Prosthetic Hand, ROMJ IST, Volume 21, Number 2, 2018, pp. 129-138 